\title{
Identification of Sapstain Fungi on Weathered Wooden Surfaces of Buildings at Jangheung and Jeju Island ${ }^{1}$
}

\author{
Jeonghee $\mathrm{YUN}^{2} \cdot$ Hee Chang $\mathrm{SHIN}^{2}$ - Won Joung $\mathrm{HWANG}^{3}$ • \\ Sae-Min YOON $^{3} \cdot$ Yeong-Suk KIM (iD ${ }^{2, \dagger}$
}

\begin{abstract}
Recently it is trend to increase wood use as carbon neutral materials, there is recognized to need necessarily durability improvement of wooden building. It is very rare to report existing on the identification of isolates causing discoloration in domestic weathered wooden building used for long period. The objective of this study was identification of fungi that cause discoloration on the exteriors of weathered domestic wooden buildings in the southern part of South Korea. Our findings can be helpful to establish protection technology for weather deterioration of domestic wooden buildings. Wood chip samples presumed to be contaminated with sapstain fungi were collected from the surface of wooden members used in wooden buildings at Jangheung, Jeollanam-do (two locations, \#13 and \#14), and Jeju Island (two locations, \#31 and \#33). The growth of microorganisms was confirmed by performing culture tests for the collected samples, and fungi were isolated, purified, and identified. The results indicated that the fungal strains isolated from wooden buildings \#13 and \#14 at Jangheung, Jeollanam-do, were $99.83 \%$ and $100 \%$ homologous to Aureobasidium melanogenum, respectively. For wooden building \#31 at Jeju Island (two locations), the fungal strain isolated was $100 \%$ homologous to A. melanogenum, which is the same species isolated from the wooden buildings at Jangheung. The fungal strain isolated from wooden building \#33 (Jeju Island) had 99.83\% homology with A. pullulans, which is commonly found in wood degraded by weather or ultraviolet rays. Our findings can be utilized as a basis for establishing protection technology in domestic wooden buildings.
\end{abstract}

Keywords: wooden building, weathered surfaces, sapstain fungi, identification, Jangheung, Jeju Island

\section{INTRODUCTION}

Since the adoption of climate change agreements, including the Paris Agreement, the use of wood products is gradually increasing for the reduction of greenhouse gas emissions and carbon neutral effect (Choi,
2021; Oh, 2021). Consequently, various deterioration phenomena that occur in wood often render its maintenance difficult for both the suppliers and consumers of wood products (Haas et al., 2019; Kim, 2017; Park et al., 2018; Ra, 2018). Wood may get deteriorated by various microorganisms, such as sapstain or molds,

\footnotetext{
1 Date Received July 12, 2021, Date Accepted October 23, 2021

2 Department of Forest Products \& Biotechnology, College of Science Technology, Kookmin University, Seoul 02707, Republic of Korea

3 Wood Engineering Division, Forest Products and Industry Department, National Institute of Forest Science, 57 Hoegi-ro, Dongdaemun-gu, Seoul 02455, Republic of Korea

$\dagger$ Corresponding author: Yeong-Suk KIM (e-mail: yskim@kookmin.ac.kr, ORCID: 0000-0002-0221-5764)
} 
Jeonghee YUN $\cdot$ Hee Chang SHIN $\cdot$ Won Joung HWANG $\cdot$ Sae-Min YOON $\cdot$ Yeong-Suk KIM

which bring about wood discoloration (Kim et al., 2015; Kim, 2018). The sapstain fungi discolor the wood tissues with various pigments as they grow through the main cellular cavities and pits of wood. The discoloration of the entire sapwood part leads to poor aesthetics or loss of product value even after sawing or cutting (Kim et al., 2019; KOFPI 2021; Zabel \& Morrell 1992). Especially, the occurrence of black spots or black discoloration, which are common in building materials; such as wooden sidings, columns, decks, and fascia boards of wooden buildings; used on the exteriors of buildings or structures, have been reported to be severe defects. These defects render maintenance difficult for users or builders of wooden buildings (Kim et al., 2018b). Botryosphaeria species, Sphaeropsis sapinea, Ophiostoma species, Ceratocystis species, Leptographium species, and Ceratocystiopsis species have been reported as the main fungi causing sapwood discoloration (Schirp et al., 2003a,b). Uzunovic et al. (1999) have reported in their paper on the identification of major microorganisms in Canada's important commercial softwood logs that were stockpiled after logging (Abies balsamea (L.) Mill., Picea mariana (Mill.) B.S.P., P. glauca (Moench) Voss, Pinus contorta Dougl. and P. banksiana Lamb.) that the most frequently occurring species belonged to the genus Ophiostoma, such as $O$. floccosum, O. ips, O. minus, O. piceae, O. piceaperdum, $O$. piliferum, and other sapstain fungi including Ceratocystis adiposa, C. coerulescens, Aureobasidium pullulans, Leptographium spp., Phacidium coniferarum, etc. were also found.

In addition, in domestic pine logs and boards, major harmful fungi, such as L. koreanum, O. floccosum, $O$. ips, O. floccosum, O. piceae, O. piliferum, O. quercus, Pesotum fragrans, etc., were identified (Kim et al. 2007). In particular, in radiata pine, which accounts for nearly half of the domestic timber imports, it is known that sapwood discoloration caused by micro- organisms is very severe unless the moisture content is reduced below the fiber saturation point via thorough artificial drying or if the surface is not treated with chemicals (Zabel and Morrell, 1992,). In a survey conducted in New Zealand, one of the major countries producing radiata pines, $S$. sapinea, O. ips, O. floccosum, O. piliferum, L. procerum, O. querci, O. coronatum, $O$. galeiforme, $O$. huntii, $O$. nicrocarpumhke, $O$. perfectum, O. piceae, O. pluriannulatum, O. setosum, $O$. stenoceras, and P. fragans were reported as the dominant species of sapstain fungi that mainly affect radiata pines (Thwaites et al., 2005). A number of papers have been reported on various species of the genus Ophiostoma that were isolated and identified from radiata pines imported from New Zealand and antimicrobial treatments used to prevent them (Kim et al., 2005; Kim, 2000; Zabel and Morrell, 1992). Moreover, other sapstain fungi, including Cladosporium sp., Trichoderma sp., and Penicillium sp., have been reported domestically (Huh et al., 2011; Jang et al., 2011; Lee et al., 2012). The causes of sapwood discoloration reported as described above are discoloration fungi that occur mainly in high temperature and high humidity environments during transportation or storage, and Humar et al. (2008) reported that the representative blue stains appearing in wooden members used in buildings are A. pullulans and Sclerophoma pithyophila. These blue stains usually appear as blue, gray, or black spots and are known to invade both conifers and hardwoods (Schmidt, 2006). A. pullulans has been reported to cause discoloration and deformation of the wood coating by infecting wood surfaces exposed to the weather or when used in buildings (Ray et al., 2004; Sharpe and Dickinson, 1992). In addition, A. pullulans and $S$. pithyophila have been selected as type strains used to test antifungal effects against blue stains according to the European standard (European Standard EN 152-1 \& 2, 1990; Kang et al., 1995). Although Aureobasidium spcies causes severe damage 
on wood to point where it was selected as a type strain, there have been no reports on the incidence and identification of this species in weathered domestic wooden building.

In investigation of weather deterioration in the wooden members used in the exteriors of wooden buildings at Jangheung, Jeollanam-do, and Jeju-do in Korea, the dark gray discoloration phenomenon was largely observed on the exteriors of wooden buildings that are heavily irradiated with sunlight. Based on this fact, the goal of this study was to identify the fungi causing discoloration occurred on the weathered exteriors of domestic wooden buildings. Because it was rare research report to characterize weather deterioration of wooden members used for long period under domestic natural environments, there is required to figure out characterization of weather deterioration and establish protection technology according to major wood species under domestic natural environments.

\section{MATERIALS and METHODS}

\subsection{Sample collection from the discolored contaminated area}

Samples were taken from the contaminated area where the surface of the weathered wooden members showed discoloration (gray-to-black spots). The sampling sites were wooden buildings \#13 (Fig. 1(A)) and \#14 (Fig. 1(B)) at Jangheung, Jeollanam-do and wooden buildings \#31 (Fig. 1(C)), and \#33 (Fig. 1(D)) at Jeju
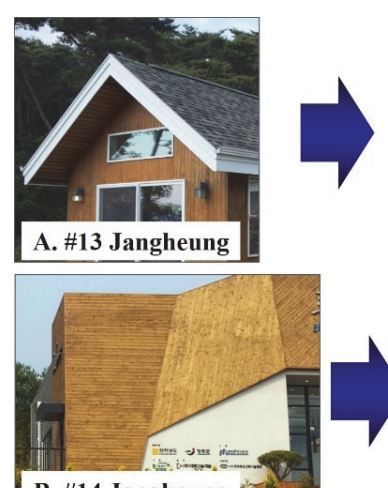

B. \#14 Jangheung
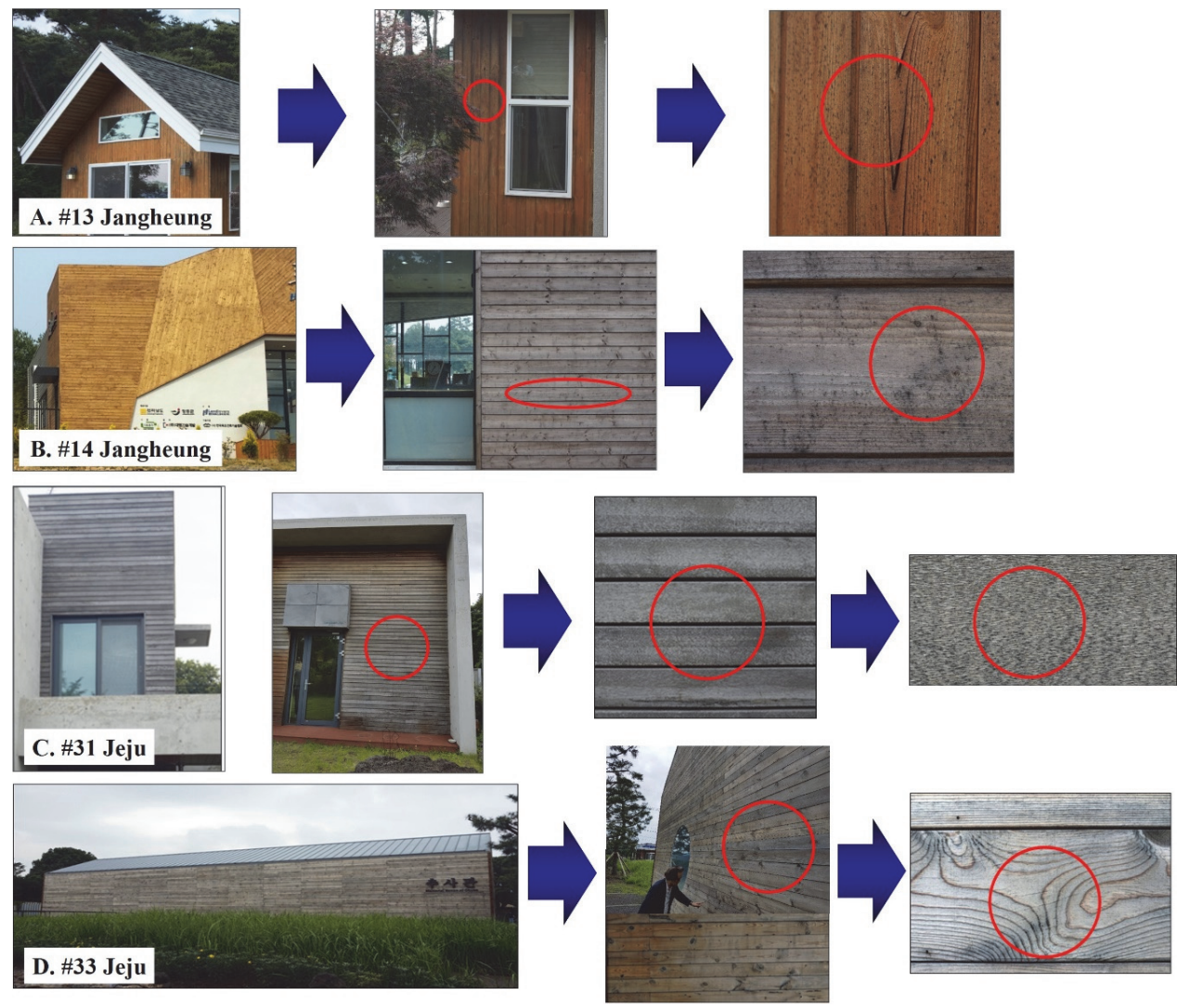

Fig. 1. Sample collection. 
Jeonghee YUN $\cdot$ Hee Chang SHIN $\cdot$ Won Joung HWANG $\cdot$ Sae-Min YOON $\cdot$ Yeong-Suk KIM

Island. The detail of the sample history was investigated throught the survey from the construction companies by co-operation with Korea Wood Building Association. These buildings were 6-10 years old of buildings \#13, \#14, and \#31 and below 5 years old of building \#33. There was no treatment on the exterior wood members used in all of buildings before used. The type of wood was imported wood such as Radiata pine, SPF (Spruce, Pine, Fir), Douglas-fir in buildings $\# 13$ and \#14, Bangkirai in building \#31, and Jejudo Japanese cedar in building \#33.

\subsection{Isolation of fungal strains}

To isolate pure strains of wood-damaging fungi from the sampling specimen, after transplanting the collected specimen into a petri dish containing sterile filter paper with moisture, samples were incubated at $26^{\circ} \mathrm{C}$ for mycelial growth, and the mycelium showing growth was inoculated into a new separation medium and cultured. Potato dextrose agar (Bacto Corporation) supplemented with $25 \mathrm{mg} / \mathrm{L}$ chloramphenicol was used to inhibit the growth of other microorganisms. After inoculation, they were cultured in an incubator, and the aforementioned transplantation and culture processes were repeated until a pure single strain was obtained.

\subsection{Identification of fungal strains}

The genomic DNA was extracted to identify the strain of the isolated wood-damaging fungi. For DNA extraction, the cell wall of the strain was decomposed using a tissue lyser, and the genomic DNA was extracted using the Qiagen DNeasy Plant Mini kit. Polymerase chain reaction (PCR) was performed to amplify the extracted genomic DNA for identifying the fungal strain. For amplification and sequencing, the ITS1 (5'-TCC GTA GGT GAA CCT GCG G-3') and ITS4 (5'-TCC TCC GCT TAT TGA TAT GC-3') primers were used. Further, we requested Macrogen Inc. to perform DNA sequencing for confirming the nucleotide sequence of the internal transcribed spacer region obtained through PCR, and based on the sequencing results, homology search was performed using the Basic Local Alignment Search Tool (BLAST) (nucleotide BLAST) of the National Center for Biotechnology Information (NCBI). In addition, phylogenetic trees were generated using the maximum likelihood statistical method in MEGA version 10.

\section{RESULTS and DISCUSSION}

The results obtained after observing the microbial growth characteristics of the pure strain isolated from the samples collected from the contaminated surfaces of weathered woods members with gray-to-black spots are shown as follows.

The test specimen was cultured in an appropriate environment to confirm the presence or absence of wood-damaging fungi in the black spots present on the specimen collected from wooden building \#13 at Jangheung, Jeollanam-do in 2017. Following a separation step performed to obtain a pure strain of fungi, the growth and presence of wood-damaging fungi (sapstain fungi) was confirmed in the specimens collected from wooden buildings \#13 and \#14 (Fig. 2(a) $\&$ 2(b)). By visual observation of the two pure strains obtained, it was confirmed that black spores were formed in both the strains, but the types of fungi cultured in the medium were different from each other. The fungus harvested from wooden building \#13 had a fluff shape at the border of the medium and was black on the inside and gray on the outside (Fig. 2(a)), whereas the fungus harvested from building \#14 had a smooth boundary between the fungus and the medium and the color of the fungus was also gray on the inside and black on the outside (Fig. 2(b)).

Samples of wooden members presumed to be con- 


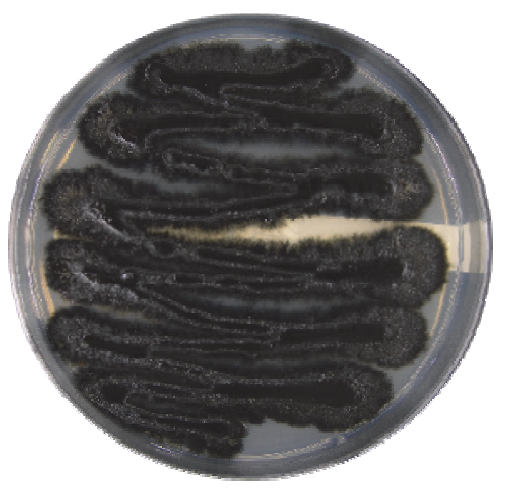

(a)

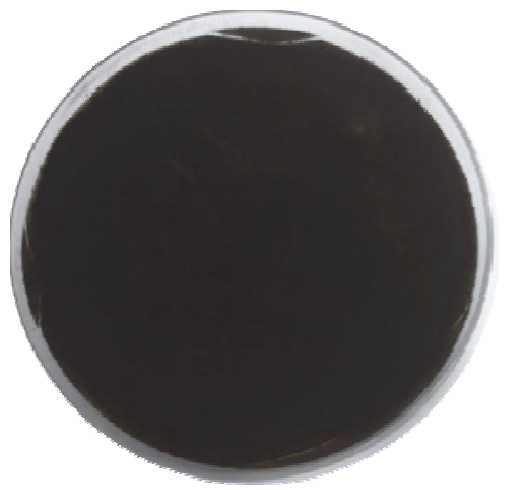

(c)

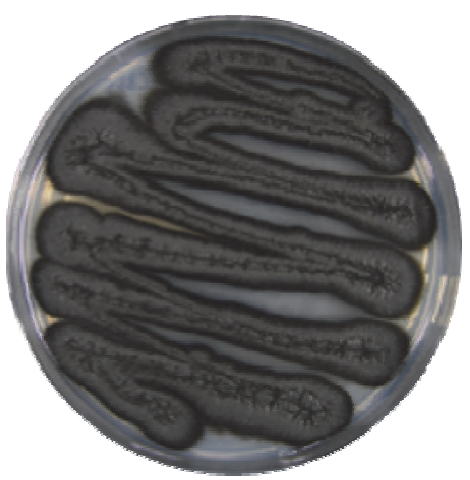

(b)

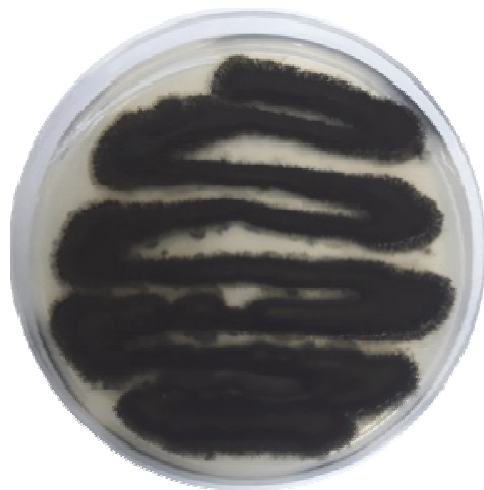

(d)

Fig. 2. Colony shape of strains isolated in cultured medium. (a) Fungi isolated from wooden building \#13; (b) Fungi isolated from wooden building \#14; (c) Fungi isolated from wooden building \#31; (d) Fungi isolated from wooden building \#33.

taminated with sapstain fungi from wooden buildings \#31 and \#33 that were investigated at Jeju Island in 2018 were collected and cultured, and the microbial growth was confirmed. After performing separation steps to obtain a single strain, wood-damaging fungi (sapstain fungi) were obtained from a total of three specimens (Fig. 2(c) \& 2(d)). From visual observation of the obtained microorganisms, the growth of black spores was observed in the two fungi isolated from wooden buildings \#31 and \#33, but the types of fungi cultured in the medium were different. The fungus from building \#31 showed the growth of spores in the black powdery medium (Fig. 2(c)), and the pure strain of fungi isolated from wooden building \#33 showed the growth pattern of black microorganisms presumed to be Aureobasidium sp. (Fig. 2(d)). It is known that colonies of the genus Aureobasdium in the early stage of culture show a creamish color from yellow to light pink and light brown, but as the incubation duration elapses, they show a very dark color gradually turning to black due to melanin secretion (Kim et al., 2018a).

A nucleotide sequence analysis was performed to identify the pure strains of wood-damaging fungi obtained by isolation. The results of comparative analysis of the nucleotide sequence, which were obtained by sequencing the ITS region and homology search using 
Jeonghee YUN $\cdot$ Hee Chang SHIN $\cdot$ Won Joung HWANG $\cdot$ Sae-Min YOON $\cdot$ Yeong-Suk KIM

Table 1. Results of BLAST analysis of the strains isolated from the wooden buildings

\begin{tabular}{|c|c|c|c|c|c|}
\hline Building No. & Accession & Description & Query coverage & E-value & Max identity \\
\hline$\# 13$ & KY659501.1 & Aureobasidium melanogenum & $100 \%$ & 0 & $99.83 \%$ \\
\hline$\# 14$ & MH855849.1 & A. melanogenum & $99 \%$ & 0 & $100 \%$ \\
\hline$\# 31$ & MH855849.1 & A. melanogenum & $100 \%$ & 0 & $100 \%$ \\
\hline$\# 33$ & KP131645.1 & A. pullulans & $100 \%$ & 0 & $99.83 \%$ \\
\hline
\end{tabular}

NCBI BLAST, with the sequences available on GenBank database are shown in Table 1 (Jang et al., 2014). Comparative analyses were performed for the obtained base sequences using NCBI BLAST. As shown in Table 1 , the fungus isolated from wooden building \#13 showed a high homology (99.83\%) with $A$. melanogenum, and this strain was found to be a strain of $A$. melanogenum. The fungus isolated from wooden building \#14 showed a $100 \%$ homology with $A$. melanogenum and was identified to be a strain of $A$. melanogenum. The fungus isolated from wooden building \#31 was confirmed to have a $100 \%$ homology with $A$. melanogenum. The fungus isolated from wooden building \#33 showed a 99.83\% homology with $A$. pullulans, and this strain was identified as $A$. pullulans. Because the fungal strains isolated from wooden buildings \#13 and \#33 did not show a 100\% homology with the previously registered $A$. melanogenum and A. pullulans, the possibility of them being a new species was considered.

The phylogenetic tree generated from the TamuraNei model using the ITS sequence of the strain isolated from wooden building \#13 is shown in Fig. 3(a). The fungus isolated from wooden building \#13 formed a group with $A$. melanogenum and was clearly identified as A. melanogenum since it showed a $99.83 \%-$ $100 \%$ homology. Fig. 3(b) shows the phylogenetic tree of the strain isolated from wooden building \#14, and this strain also formed a group with $A$. melanogenum in a form similar to that formed by the strain isolated from wooden building \#13. It was clearly identified to be $A$. melanogenum, showing a $100 \%$ homology.

Fig. 3(c) shows the phylogenetic tree of the strain isolated from wooden building \#31. This strain also formed a group with $A$. melanogenum, which belongs to the genus Aureobasidium, a sapstain fungus mainly found in above-ground exterior materials and is predominantly found in the Netherlands, South Africa, Australia, and Norway, and their number is reported to be increasing continuously (van Nieuwenhuijzen et al., 2016). A. melanogenum is also known to dominate oil-treated woods, but it is not yet clearly confirmed whether this is due to its better adhesion or viability than that of other Aureobasidium species (van Nieuwenhuijzen et al., 2016). The researchers speculate that extracellular polymeric substances, such as $\beta$-glucan and acidic polysaccharides, may have enhanced its adhesion. In addition, reports suggest that it may be necessary to examine the possibility that $A$. melanogenum produces more melanin or a different type of melanin compared to that produced by other Aureobasidium species against specific stresses, such as UV irradiation or oxidizers. A. melanogenum has been reported to have the ability of utilizing xylan, which is a major hemicellulose, as a single carbon source, and it is gaining more attention (Saika et al., 2020).

The phylogenetic tree of the strain isolated from wooden building \#33 is shown in Fig. 3(d). This strain formed a group with the highest homology to the $A$. pullulans strain and showed a tendency to coexist with the A. melanogenum group similar to the strains isolated from wooden buildings \#13 and \#31. According to some researchers, A. pullulans is a species that is often found in mild osmotic environments. It has been found to have salt resistance even at the highest salt 
Identification of Sapstain Fungi on Weathered Wooden Surfaces of Buildings at Jangheung and Jeju Island

(a)

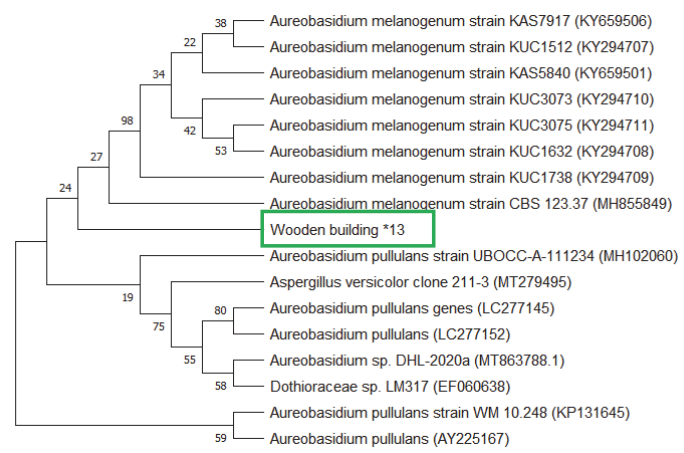

(b)

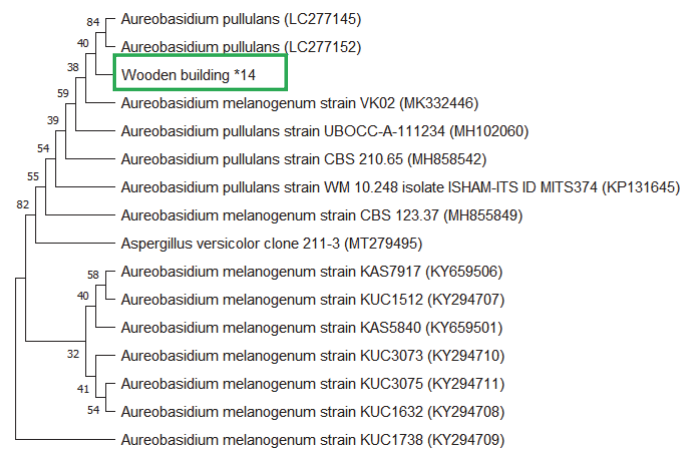

(c)

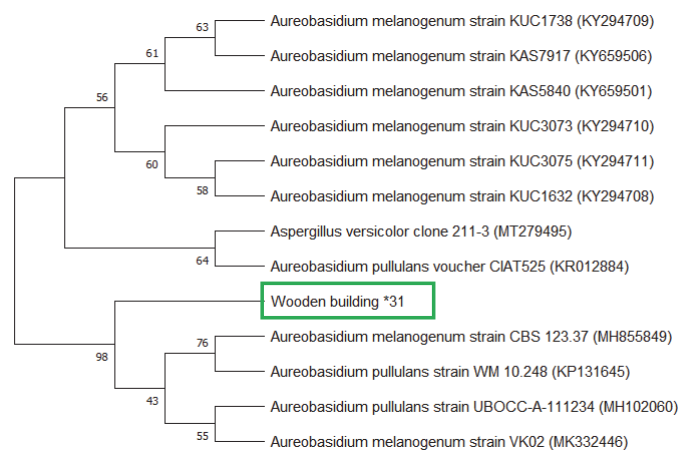

(d)

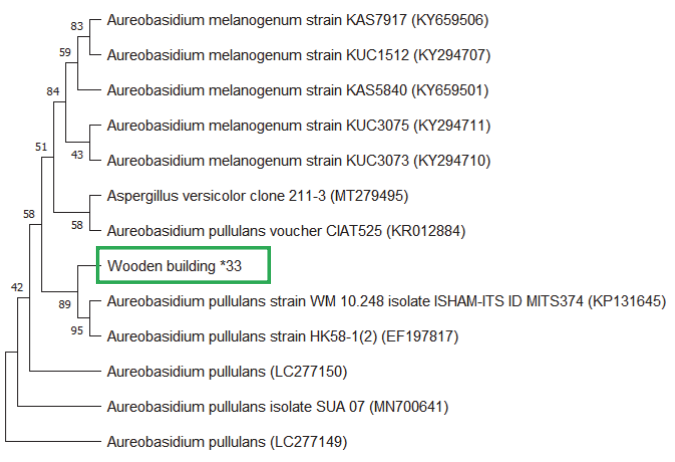

Fig. 3. The phylogenetic tree of the strains isolated from wooden buildings based on internal transcribed spacer region sequences. (a) wooden building \#13; (b) wooden building \#14; (c) wooden building \#31; (d) wooden building \#33. 
Jeonghee YUN $\cdot$ Hee Chang SHIN $\cdot$ Won Joung HWANG $\cdot$ Sae-Min YOON $\cdot$ Yeong-Suk KIM

concentration $(17 \% \mathrm{NaCl})$ among the four major strains of Aureobasidium, i.e., A. pullulans, A. melanogenum, A. subglaciale, and $A$. namibiae. On the other hand, A. melanogenum has been mainly isolated from oligotrophic environments, such as water, and has been reported to grow at $37^{\circ} \mathrm{C}$ unlike other varieties (Gostinčar et al., 2014). In 2015, A. pullulans was isolated from indoor wood, where black discoloration was observed in a wooden cultural heritage site in Korea with a wood surface moisture content exceeding $15 \%$ (Kim et al., 2015). In this study, apperance of Aureobasidium species at the sampling sites of Jangheung and Jeju Island might be able to be affected by climate change. According to the meteorological data, there was oberved that temperature, precipitation, and humidity in both sampling sites were increased from 1991 through 2021 (Jangheung: $12.8^{\circ} \mathrm{C}, 1392.0$ $\mathrm{mm}, 71.0 \%$ in 1991 to $13.3^{\circ} \mathrm{C}, 1471.8 \mathrm{~mm}, 71.9 \%$ in 2021; Jeju Island: $12.4^{\circ} \mathrm{C}, 1771.4 \mathrm{~mm}, 68.5 \%$ in 1991 to $13.9^{\circ} \mathrm{C}, 1989.6 \mathrm{~mm}, 69.8 \%$ in 2021 ).

In general, the species frequently reported to be hazardous in weather deterioration is A. pullulans, and wooden building \#33 at Jeju Island was found to have the same strain. However, the strains isolated from wooden building \#13 at Jangheung, Jeollanam-do and wooden building \#31 at Jeju Island were A. melanogenum, which was previously classified as A. pullulans since some gene sequences differed enough to be classified as another species but was recently found to be one of the main variants of Aureobasidium (Gostinčar et al., 2014). Because it exist many varieties of the genus Aureobasidium, there are required to confirm colony morphological analysis as well as genomic sequencing for distinguishing the species in this genus (Kim et al., 2018a). Therefore, morphological and physiological analysis and genomic sequencing using RPB2, LSU-rRNA, and ITS are expected to be applicable to comparative identification with strains occurring in similar damaging woods in other regions in further studies and to investigate occurrence characteristics of strains according to domestic environments and wood species. In case of $A$. melanogenum, the degradation pattern of Douglas fir by this strain was first reported in Korea in 2017, and it has also been reported to be an erosive soft-rot Type II in pine sapwood (Lee et al., 2017). From these results, it was confirmed that A. melanogenum and A. pullulans coexist in Korea, suggesting the necessity for more identification studies on wood-damaging strains that present in the weathered domestic woods. This strain also formed a group with A. melanogenum, which belongs to the genus Aureobasidium, a sapstain fungus mainly found in above-ground exterior materials and is predominantly found in the Netherlands, South Africa, Australia, and Norway, and their number is reported to be increasing continuously (van Nieuwenhuijzen et al., 2016). In some studies, Aureobasidium strains have been isolated from wooden surfaces in the Netherlands and Thailand (Peterson et al., 2013; van Nieuwenhuijzen et al., 2016). The sampling sites in the Netherlands is located between $52^{\circ} 5^{\prime} 34.3536^{\prime \prime} \mathrm{N}$ and $5^{\circ} 6^{\prime} 16.1280^{\prime \prime} \mathrm{E}$, and there are the average annual temperature of $15.6^{\circ} \mathrm{C}$, the average monthly precipitation range of 3-143 $\mathrm{mm}$, the average monthly relative humidity range of $34.8-68.1 \%$. The sampling sites in Thailands is located between $14^{\circ} 58^{\prime} 47.6400^{\prime \prime} \mathrm{N}$ and $102^{\circ} 5^{\prime} 51.9756 \mathrm{E}$, and there are the average annual temperature of $26.7^{\circ} \mathrm{C}$, the average monthly precipitation range of $6-235 \mathrm{~mm}$, the average monthly relative humidity range of $54.9-81.3 \%$. In this study, the sampling sites are located between $34^{\circ} 30^{\prime} 35^{\prime \prime} \mathrm{N}$ and $126^{\circ} 31^{\prime} 19 \mathrm{E}$ in Jangheung and $33^{\circ} 15^{\prime} 11.99^{\prime \prime} \mathrm{N}$ and $126^{\circ} 33^{\prime} 42.52 \mathrm{E}$ in Jeju Island. The meteorological factors are the annual temperature range of -6.7-30. $6^{\circ} \mathrm{C}$, the average monthly precipitation range of $11.3-374.8 \mathrm{~mm}$, the relative humidity range of $23-90 \%$ in Jangheung, and these are the annual temperature range of $2.8-29.4^{\circ} \mathrm{C}$, the average monthly precipitation 
Identification of Sapstain Fungi on Weathered Wooden Surfaces of Buildings at Jangheung and Jeju Island

range of $61.7-238.9 \mathrm{~mm}$, the relative humidity range of $25-99 \%$ in Jeju Island.

\section{CONCLUSION}

To identify the pure strains of wood-damaging fungi obtained after isolating them from samples collected from wooden members used in wooden buildings in southern area of South Korea, the nucleotide sequence was analyzed by sequencing the ITS region. The fungi collected from wooden buildings \#13, \#14 (Jangheung), and \#31 (Jeju Island) showed 99.83\%, 100\% and $100 \%$ nucleotide sequence homologies with $A$. melanogenum strains, respectively, and these strains were confirmed to be $A$. melanogenum strains. With respect to the fungus isolated from wooden building \#33 (Jeju Island), it showed a $99.83 \%$ homology with the $\mathrm{A}$. pullulans strain, and this strain was confirmed to be an A. pullulans strain. In general, the species frequently reported to be harmful with respect to weather deterioration is $A$. pullulans, and the strain isolated from wooden building \#33 at Jeju Island was found to be the same strain. However, the strain isolated from wooden buildings \#13 and \#14 at Jangheung, Jeollanam-do and wooden building \#31 at Jeju Island was $A$. melanogenum, which was previously classified as $A$. pullulans but has recently been found to have some different gene sequences. From these results, it was found that A. melanogenum and A. pullulans coexist in Korea, suggesting the necessity for further identification studies on wood-damaging strains that appear in the weathered domestic woods in southern area of South Korea. Also, it implicates that the need for varnish development and antifungal treatment of wood targeting microorganisms that cause these black spots.

\section{ACKNOWLEDGMENT}

This study was carried out with the support of the
R\&D Program for Forest Science Technology (Project No. 2020261B10-2122-AC02 and 2019150B10-2123-0301) provided by the Korea Forest Service (Korea Forestry Promotion Institute).

\section{REFERENCES}

Choi, J.M. 2021. Necessity and improvements of wood architecture for carbon neutral. Wood Industry Online Seminar. The Korean Society of Wood Science and Technology, August 11, 2021.

European Committee for standardization. 1996. Test methods for determining the protective effectiveness of a preservative treatment against blue stain in service - Part 1: Brushing procedure. EN 152-1. Brussels, 16.

Gostinčar, C., Ohm, R.A., Kogej, T., Sonjak, S., Turk, M., Zajc, J., Zalar, P., Grube, M., Sun H., Han, J., Sharma, A., Chiniquy, J., Ngan, C.Y., Lipzen, A., Barry, K., Grigoriev, I.V., Gunde-Cimerman, N. 2014. Genome sequencing of four Aureobasidium pullulans varieties: Biotechnological potential, stress tolerance, and description of new species. BMC genomics 15(1): 1-29.

Haas, D., Mayrhofer, H., Habib, J., Galler, H., Reinthaler, F.F., Fuxjäger, M.L., Buzina, W. 2019. Distribution of building-associated wood-destroying fungi in the federal state of Styria, Austria. European Journal of Wood and Wood Products 77(4): 527-537.

Huh, N., Jang, Y., Lee, J., Kim, G.H., Kim, J.J. 2011. Phylogenetic analysis of major molds inhabiting woods and their discoloration characteristics. Part 1. Genus Trichoderma. Holzforschung 65(2): 257-263.

Humar, M., Vek, V., Bučar, B. 2008. Properties of blue-stained wood. Drvna industrija: Znanstveni časopis za pitanja drvne tehnologije 59(2): 75-79. Jang, Y., Huh, N., Lee, J., Lee, J.S., Kim, G.H., Kim, J.J. 2011. Phylogenetic analysis of major molds inhabiting woods and their discoloration characteristics. 
Jeonghee YUN $\cdot$ Hee Chang SHIN $\cdot$ Won Joung HWANG $\cdot$ Sae-Min YOON $\cdot$ Yeong-Suk KIM

Part 2. Genus Penicillium. Holzforschung 65(2): 265-270.

Jang, Y., Jang, S., Lee, J., Lee, H., Lee, H., Lee, Y.M., Hong, J., Min, M., Lim, Y.W., Kim, C, Kim, J.J. 2014. Wood decay fungi in South Korea: Polypores from Seoul. Mycobiology 42(2): 140-146.

Kang, K.Y., Lee, D.H., Oh, J.S. 1995. Antifungal metabolisms of Streptomyces rimosus against sapstain and mold fungi(I)-Antifungal efficacy of secondary metabolites. Journal of the Korean Wood Science and Technology 23(1): 42-48.

Kim, G.H., Kim, J.J., Breuil, C. 2007. Sap-staining fungi from logs and boards of two commercially important pines in Korea. Holzforschung 61(3): 333-336.

Kim, G.H., Kim, J.J., Lim, Y.W., Breuil, C. 2005. Ophiostomatoid fungi isolated from Pinus radiata logs imported from New Zealand to Korea. Canadian Journal of Botany 83(3): 272-278.

Kim, J.J. 2000. Biological discoloration of radiata pine and its prevention. Ph.D. Thesis, Korea University, Seoul, Korea, pp. 142.

Kim, J.S., Lee, M., Song, M.Y., Kwon, S.W., Kim, S.J., Hong, S.B., Park, B.Y., Yun, B.S. 2018a. Isolation and identification of Aureobasidium spp. from flowers of the Jeolla-do province in Korea. The Korean Journal of Mycology 46(4): 415-425.

Kim, M.J., Shin, H.K., Choi, Y.S., Kim, G.C., Kim, G.H. 2015. Predicting influence of changes in indoor air temperature and humidity of wooden cultural heritages by door opening on their conservation environment. Journal of the Korean Wood Science and Technology 43(6): 798-803.

Kim, Y.S. 2017. Current researches on the weathering of wood. Journal of the Korean Wood Science and Technology 45(5): 483-494.

Kim, Y.S. 2018. Current researches on the protection of exterior wood from weathering. Journal of the Korean Wood Science and Technology 46(5): 449-470.
Kim, Y.S., Kim, G.H., Kim, Y.S. 2019. Wood Protection Science. Chonnam National University Press, Gwangju, South Korea, pp. 74-78.

Kim, Y.S., Shin, H.C., Park, S., Kim, J.H., Kim, S. 2018 b. Research on the deterioration of commercial woods and wooden building by natural and accelerated weathering. Research report 20-12, National Institute of Forest Science, Seoul, South Korea, pp. 5-226.

Korea Forestry Promotion Institute (KOFPI). 2021. https://www.kofpi.or.kr/info/imupStory/wood_04 01view.do

Lee, Y.M., Jang, Y., Kim, G.H., Kim, J.J. 2012. Phylogenetic analysis and discoloration characteristics of major molds inhabiting woods. Part 3. Genus Cladosporium. Holzforschung 66(4): 537-541.

Lee, Y.M., Lee, H., Heo, Y.M., Hong, J.H., Jang, S., Kang, K.Y., Kim, J.J. 2017. Phylogenetic analysis of wood-inhabiting molds and assessment of soft-rot wood deterioration. Part 5. Genus Aureobasidium. Holzforschung 71(5): 437-443.

Oh, S.C. 2021. Environmental architecture for carbon neutral: Wood construction. Wood Industry Online Seminar, The Korean Society of Wood Science and Technology, August 11, 2021.

Park, S.Y., Hong, C.Y., Kim, S.H., Choi, J.H., Lee, H.J., Choi, I.G. 2018. Studies on photoprotection of walnut veneer exposed to UV light. Journal of the Korean Wood Science and Technology 46(3): 221-230.

Peterson, S.W., Manitchotpisit, P., Leathers, T.D. 2013. Aureobasidium thailandense sp. nov. isolated from leaves and wooden surfaces. International Journal of Systematic and Evolutionary Microbiology 63(Pt_2): 790-795.

Ra, J.B. 2018. Determination of driving rain index by using hourly weather data for developing a good design of wooden buildings. Journal of the Korean Wood Science and Technology 46(6): 627-636. Ray, M.J., Dickinson, D.J., Buck, M. 2004. 
Identification of Sapstain Fungi on Weathered Wooden Surfaces of Buildings at Jangheung and Jeju Island

Aureobasidium or Hormonema? A Genetic Approach.

The International Research Group on Wood Protection, Stockholm, IRG/WP 04-10529, 13.

Saika, A., Fukuoka, T., Mikome, S., Kondo, Y., Habe, H., Morita, T. 2020. Screening and isolation of the liamocin-producing yeast Aureobasidium melanogenum using xylose as the sole carbon source. Journal of bioscience and bioengineering 129(4): 428-434.

Schirp, A., Farrell, R.L., Kreber, B., Singh, A.P. 2003 b. Advances in understanding the ability of sapstaining fungi to produce cell-wall degrading enzymes. Wood and Fiber Science 35(3): 434-444.

Schirp, A., Farrell, R.L., Kreber, B. 2003a. Effects of New Zealand sapstaining fungi on structural integrity of unseasoned radiata pine. Holz als Rohund Werkstoff 61(5): 369-376.

Schmidt, O. 2006. Wood and tree fungi (p. 334). SpringerVerlag Berlin Heidelberg.

Sharpe, P.R., Dickinson, D.J. 1992. Blue stain in service on wood surface coatings Part 1. The nutritional requirements of Aureobasidium pullulans. The International Research Group on Wood Protection, Stockholm, IRG/WP 92-1556, 14.

Thwaites, J.M., Farrell, R.L., Duncan, S.M., Reay, S.D., Blanchette, R.A., Hadar, E., Hadar, Y., Harrington, T. C., McNew, D. 2005. Survey of potential sapstain fungi on Pinus radiata in New Zealand. New Zealand Journal of Botany 43(3): 653-663.

Uzunovic, A., Yang, D-Q., Gagné, P., Breuil, C., Bernier, L., Byrne, A., Gignac, M., Kim, S.H. 1999. Fungi that cause sapstain in Canadian softwoods. Canadian Journal of Microbiology 45(11): 914-922 van Nieuwenhuijzen, E.J., Houbraken, J.A., Meijer, M., Adan, O.C., Samson, R.A. 2016. Aureobasidium melanogenum: A native of dark biofinishes on oil treated wood. Antonie van Leeuwenhoek 109(5): 661-683.

Zabel, R.A., Morrell, J.J. 1992. Wood microbiology: Decay and its prevention. Academic Press, Inc., San Diego, CA, U.S.A, pp. 476. 